
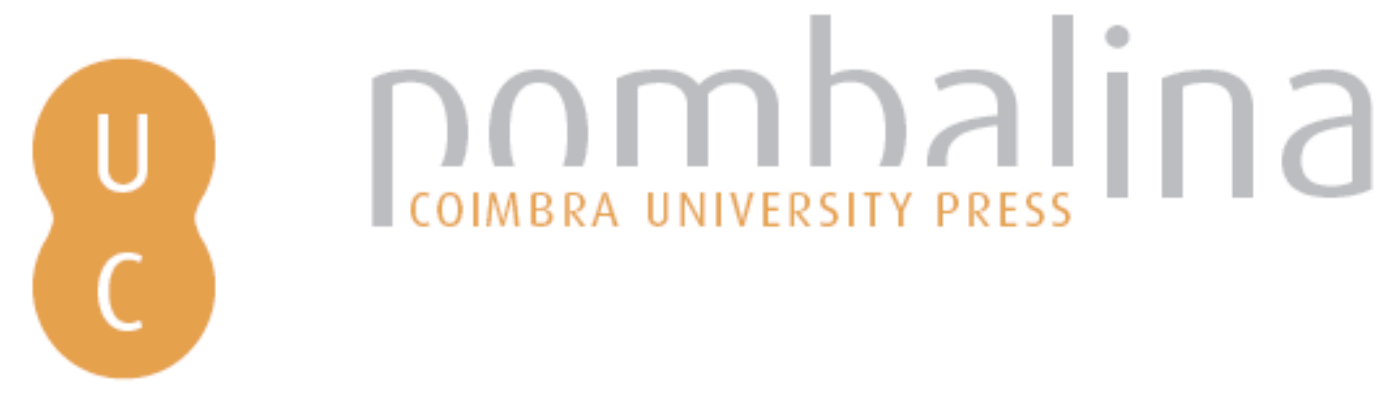

\title{
Tipos de objetos cognatos e de objetos hipónimos em português europeu
}

Autor(es): Choupina, Celda Morgado

Publicado por: Imprensa da Universidade de Coimbra

URL

persistente: URI:http://hdl.handle.net/10316.2/32246

DOI: $\quad$ DOI:http://dx.doi.org/10.14195/978-989-26-0714-6_3

Accessed : $\quad$ 26-Apr-2023 12:51:03

A navegação consulta e descarregamento dos títulos inseridos nas Bibliotecas Digitais UC Digitalis, UC Pombalina e UC Impactum, pressupõem a aceitação plena e sem reservas dos Termos e Condições de Uso destas Bibliotecas Digitais, disponíveis em https://digitalis.uc.pt/pt-pt/termos.

Conforme exposto nos referidos Termos e Condições de Uso, o descarregamento de títulos de acesso restrito requer uma licença válida de autorização devendo o utilizador aceder ao(s) documento(s) a partir de um endereço de IP da instituição detentora da supramencionada licença.

Ao utilizador é apenas permitido o descarregamento para uso pessoal, pelo que o emprego do(s) título(s) descarregado(s) para outro fim, designadamente comercial, carece de autorização do respetivo autor ou editor da obra.

Na medida em que todas as obras da UC Digitalis se encontram protegidas pelo Código do Direito de Autor e Direitos Conexos e demais legislação aplicável, toda a cópia, parcial ou total, deste documento, nos casos em que é legalmente admitida, deverá conter ou fazer-se acompanhar por este aviso.

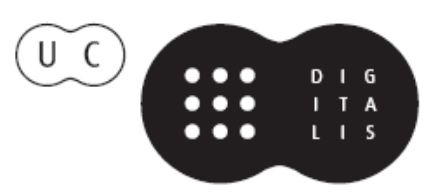




\section{ESTUDOS DE \\ LINGUÍSTICA}

VOLUME II

CONCEIÇÃO CARAPINHA

ISABEL A. SANTOS

COORD.

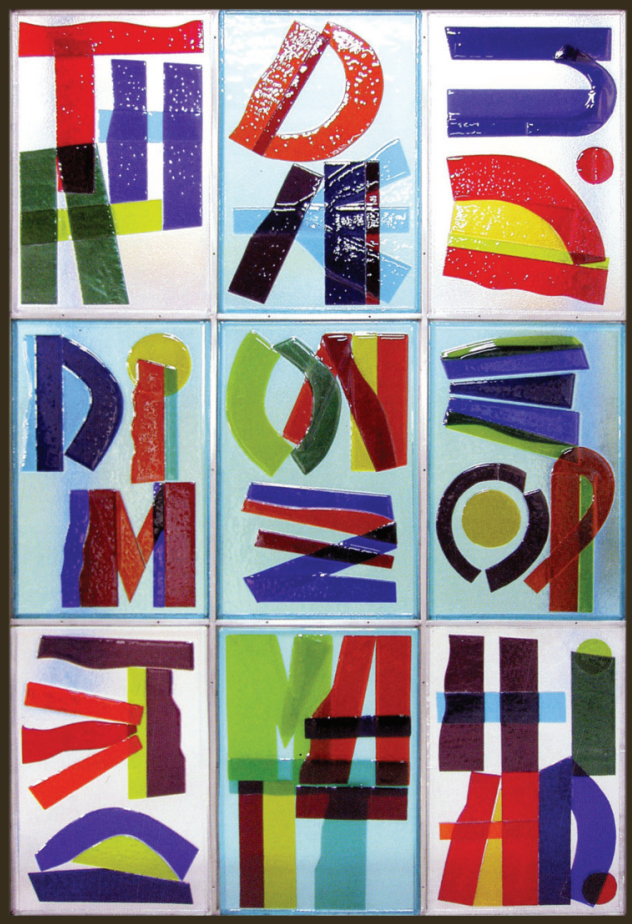




\title{
TIPOS DE OBJETOS COGNATOS E DE OBJETOS HIPÓNIMOS EM PORTUGUÊS EUROPEU
}

\author{
Celda Morgado Choupina
}

Centro de Linguística da Universidade do Porto

Escola Superior de Educação do Porto celda@ese.ipp.pt

\section{Introdução}

O presente estudo tem como objetivo analisar alguns aspetos sintáticos dos objetos $\operatorname{cognatos}^{29}$ (OC) e dos objetos hipónimos (OH) em Português Europeu (PE).

A principal hipótese a ser explorada é a de que em PE se justificam quatro construções distintas (cf. Choupina, 2012a); 2013), com propriedades comuns mas também com propriedades que as diferenciam: objetos cognatos verdadeiros (OC verdadeiros); objetos cognatos aparentados (OC aparentados); objetos hipónimos $(\mathrm{OH})$ e objetos cognatos preposicionais (OCP) (cf. Quadro 1. abaixo).

29 Utilizamos o termo 'objeto' como uma noção sintática, designando um constituinte interno ao SV (argumento ou não argumento); 'cognato' aplica-se, tradicionalmente, a palavras que têm, etimologicamente, uma origem comum. Neste texto, designaremos como 'objeto cognato' os constituintes internos pospostos e justapostos ao verbo que contêm um nome cognato morfológico (etimológico ou não) do verbo (sonhar - sonho; chover - chuva; dançar-dança...) ou um nome que se relaciona semanticamente com o verbo e não pode ser substituído por um cognato morfológico (dormir - sono). 
Quadro 1 - Tipos de construções cognatas e hipónimas em PE

\begin{tabular}{|c|c|c|c|c|}
\hline & \multicolumn{4}{|c|}{ Tipos de construções cognatas e hipónimas em PE } \\
\hline & $\begin{array}{l}\text { Objetos cognatos } \\
\text { verdadeiros } \\
\text { (OC verdadeiros) }\end{array}$ & $\begin{array}{l}\text { Objetos cognatos } \\
\text { aparentados } \\
\text { (OC aparentados) }\end{array}$ & \begin{tabular}{|l|} 
Objetos \\
bipónimos \\
(OH) \\
\end{tabular} & \begin{tabular}{|l|} 
Objetos cognatos \\
preposicionais \\
(OCP) \\
\end{tabular} \\
\hline $\begin{array}{l}\text { Propriedades } \\
\text { gerais }\end{array}$ & $\begin{array}{l}\text { objetos morfologi- } \\
\text { camente (ou não) } \\
\text { relacionados com } \\
\text { o V, com restri- } \\
\text { ções sintático- } \\
\text {-semânticas }\end{array}$ & $\begin{array}{l}\text { objetos morfolo- } \\
\text { gicamente rela- } \\
\text { cionados com o } \\
\text { verbo, mas sem } \\
\text { restrições sintáti- } \\
\text { co-semânticas }\end{array}$ & $\begin{array}{l}\text { objetos que ex- } \\
\text { primem um sub- } \\
\text { tipo da entidade } \\
\text { denotada pelo } \\
\text { nome (regressivo } \\
\text { ou não) formado } \\
\text { a partir do V }\end{array}$ & $\begin{array}{l}\text { objetos morfologi- } \\
\text { camente relaciona- } \\
\text { dos com o V, com } \\
\text { restrições sintáti- } \\
\text { co-semânticas e } \\
\text { encabeçados por } \\
\text { preposição }\end{array}$ \\
\hline $\begin{array}{l}\text { Exemplos em } \\
\text { PE }\end{array}$ & $\begin{array}{l}\text { sonhar um so- } \\
\text { nho... } \\
\text { chover uma chu- } \\
\text { va... }\end{array}$ & $\begin{array}{l}\text { dançar uma dança } \\
\text { comer uma co- } \\
\text { mida }\end{array}$ & $\begin{array}{l}\text { dançar um tango } \\
\text { comer uma la- } \\
\text { sanha }\end{array}$ & $\begin{array}{l}\text { caminhar por um } \\
\text { caminho difícil }\end{array}$ \\
\hline
\end{tabular}

No sentido de fundamentar esta proposta, as construções serão analisadas, nas secções seguintes, segundo os critérios de definitude e de modificação.

Far-se-á ainda, no ponto 4., uma breve reflexão sobre a proposta que Hale e Keyser $(1993 ;$ 2002) apresentam para algumas destas construções em Inglês, num quadro lexicalista.

\section{OC e construções aparentadas: uma primeira abordagem}

\subsection{Dados ilustrativos}

Há objetos cognatos em PE e em várias línguas do mundo, como os exemplos (1) a (4) mostram.

(1) [Português Europeu]

a) Chovia uma chuva miudinha.

b) Dormimos um sono reparador. (Duarte / Brito, 2003:185)

(2) [Espanhol]

a) Reir la risa de un niño. (Mendikoetxea, 1999: 1578)

[Rir o riso de uma criança] 
b) Juan cantó una canción. (Gallego, 2008: 6)

[O João cantou uma canção]

\section{(3) [Francês]}

a) Pleurer toutes les larmes de son corps. (Grevisse / Goosse, 1993:393)

[Chorar todas as lágrimas do seu corpo]

b) Il a dansé une grande danse. (Pereltsvaig, 2001)

[Ele dançou uma grande dança]

(4) [Inglês]

a) She slept the sleep of the just. (Hale / Keyser, 2002: 71)

[Ela dormiu o sono dos justos]

b) He laughed his last laugh. (Hale / Keyser, 2002: 71)

[Ele riu o seu último riso]

Os exemplos (1) a (4) apresentam o que normalmente é denominado objetos cognatos (Hale / Keyser, 1993; 2002) ou argumentos sombra (Pustejovsky, 1998).

Alguns dos objetos apresentados nos exemplos são da mesma família morfológica dos verbos que os precedem, como em chover-chuva (1a); reir-risa (2a), cantar-canción (2b), danser-danse (3b); to sleep-sleep (4a), to laugh-laugh (4b). Por esta razão, estes objetos, que acompanham Vs tradicionalmente considerados de 0 argumentos (chover) ou de 1 argumento externo (como os inergativos reir, to sleep, etc), são claramente pleonásticos e altamente restringidos do ponto de vista sintático. No entanto, a relação morfológica entre verbo e nome não é a mesma em todas as línguas e para todos os pares $\mathrm{V}-\mathrm{N}$; por exemplo, se em Inglês to sleep-sleep apresentam o mesmo radical, exibindo homonímia perfeita, em PE dormir-sono e em espanhol dormir-sueño apenas se relacionam semanticamente.

Os exemplos revelam, desde já, algumas diferenças entre as línguas ilustradas, sendo que, neste texto, debruçar-nos-emos sobretudo sobre os dados do Português Europeu. 


\subsection{Restrições distribucionais dos OC verdadeiros em PE}

Os exemplos do PE anteriormente apresentados ilustram objetos cognatos constituídos por um determinante indefinido, um nome e um adjetivo que o restringe, o que revela, desde já, que a definitude e a modificação poderão ser condição sine qua non para a boa formação de alguns tipos de construções cognatas, nesta língua ${ }^{30}$. No entanto, tal não se verificará para todos os tipos de cognatos.

Com efeito, os testes de definitude e de modificação apresentados a seguir mostram que em PE o OC com o verbo chover (1a) deve ser indefinido e modificado para ser aceitável:

(5) a) *Chovia a chuva miudinha.

b) *Chovia a chuva.

c) *Chovia uma chuva.

Também para (1b) se verificam as mesmas restrições (cf. testes em (6)), embora estejamos perante uma construção diferente da anterior, dada a relação semântica, e não morfológica, que o nome estabelece com o verbo:

(6) a) *Dormimos o sono reparador.

b) *Dormimos o sono.

c) */?Dormimos um sono.

Ao nível de variação regional, dormir um sono é aceitável, enquanto expressão que designa um curto espaço de tempo em que um sujeito ${ }^{31}$

30 Os OC apresentam restrições sintáticas e semânticas específicas e estabelecem relações de proximidade com as paráfrases por verbos leves (dar, ter, fazer...), bem como com as expressões fixas (dormir o sono dos justos, morrer de uma morte santa, chorar lágrimas de crocodilo...). Estas três construções podem ser analisadas, ao nível da combinação livre e da rigidez de estruturação, como integrando um continuum, sendo que os OC com verbos cognatos estariam num dos polos, as expressões fixas no outro e as paráfrases por verbo leve numa fase intermédia de fixação.

${ }^{31}$ Regionalmente, a estrutura é relativa aos bebés ou idosos, que dormem depois das refeições: dormir um sono/dormir um soninho. 
dorme, habitualmente depois da refeição do almoço; pode ser sinónimo de sesta. Em PE e nesta estrutura, não é disponibilizado o cognato morfológico dormida, (7).

(7) *Dormimos uma dormida reparadora.

Consideraremos as estruturas cognatas com os verbos chover e dormir, cognato morfológico e cognato semântico respetivamente, o mesmo tipo de OC - os OC verdadeiros.

Embora a construção com um modificador restritivo pareça ser uma exigência destes objetos quer em PE quer nas outras línguas apresentadas em (1) a (4), o critério da definitude não parece ser absolutamente uniforme em todas as línguas românicas; veja-se, entre outros, o exemplo em espanhol (2a), aqui repetido com a aplicação dos testes:

(8) a) Reir la risa de un niño. [Rir o riso de uma criança]

b) *Reir la risa. [*Rir o riso]

c) *Reir una risa de un niño. [*Rir um riso de uma criança]

Também segundo Real-Puigdollers (2008: 170), as construções com cognatos não mostram uniformemente uma restrição de definitude. Mesmo o Inglês apresenta construções em que o OC é constituído por um determinante definido ou um possessivo, desde que combinado com um restritor adjetival ou preposicional (9) e (10):

(9) a) She slept the sleep of the just. [Ela dormiu o sono dos justos]

b) *She slept the sleep. [*Ela dormiu o sono]

(10) a) He laughed his last laugh. [Ele riu o seu último riso]

b) *He laughed his laugh. / *the laugh. [*Ele riu o seu riso / *o riso]

O exemplo (3a), do Francês, apresenta um determinante definido antecedido do quantificador universal toutes, que nos parece ser decisivo para a gramaticalidade da construção com artigo definido, além da já referida modificação, como mostra a agramaticalidade de (11b) e (11c): 
(11) a) Pleurer toutes les larmes de son corps. [Chorar todas as lágrimas do seu corpo]

b) *Pleurer les larmes de son corps. [*Chorar as lágrimas do seu corpo]

c) *Pleurer les larmes. [*Chorar as lágrimas]

Os exemplos discutidos em (8) a (11) não ilustram exatamente o mesmo tipo de construções analisadas em (5) e (6), devendo haver um estudo exaustivo sobre aqueles exemplos. Parece-nos que as construções de (8) a (11) são expressões lexicalizadas / idiomáticas que ocorrem em determinada língua (ou conjunto de línguas), não estando, assim, sujeitas às mesmas restrições de boa formação que os OC verdadeiros. Se estivermos corretos, a análise contrastiva de Real-Puigdollers (2008), fundamentada apenas em exemplos de tipo (8) a (11), poderá não ser significativa (veja-se Choupina [2013] para um desenvolvimento desta reflexão).

Interessante também parece ser a subclasse do nome que aparece como núcleo destes objetos e o seu comportamento e propriedades linguísticas ao nível morfossintático e semântico. O nome-núcleo destes objetos pertence aos nomes comuns, daí que permita a coocorrência com modificadores adjetivais e preposicionais. Quanto à subclasse, encontramos nomes contáveis (danse, canción) e nomes não contáveis (chuva, risa, sleep) ou recategorizados em não contáveis (lágrimas). Sabemos que as entidades designadas pelos nomes contáveis podem contar-se, pelo que podem coocorrer com numerais e indefinidos; as entidades denotadas pelos nomes não contáveis são consideradas "grandezas contínuas, não discretas” (Duarte / Oliveira, 2003: 218), pelo que, não sendo possível enumerá-las, podem coocorrer com quantificadores indefinidos, mas não com cardinais. No exemplo (1a), o falante está a referir-se a porções padronizadas de chuva, denominadas gotas ou pingos, sendo por isso gramatical a construção com determinante e modificador restritivo. (cf. Duarte / Oliveira, 2003: 212 e ss. para uma distinção destas subclasses).

OS OC verdadeiros surgem na posição de OD, pertencem à categoria dos SN e podem apresentar diferentes configurações estruturais, como em (12) a (14): 
(12) Chovia uma chuva miudinha.

(13) Chovia uma chuva de gotas pesadas ${ }^{32}$.

(14) Chovia uma chuva que não me molhava ${ }^{33}$.

Em (12) encontramos um objeto cognato composto por nome antecedido de determinante indefinido e seguido de adjetivo ( $\mathrm{SN}=\left[\right.$ Det $\left._{\text {ind }}+\mathrm{N}+\mathrm{Adj}\right]$ ); o núcleo do OC de (13) está seguido de SP $\left(\mathrm{SN}=\left[\mathrm{Det}_{\text {ind }}+\mathrm{N}+\mathrm{SP}\right]\right)$ e o de (14) de uma oração relativa adjetiva restritiva $\left(\mathrm{SN}=\left[\right.\right.$ Det $\left.\left.\left._{\text {ind }}+\mathrm{N}+\mathrm{OR}\right)\right]\right) . \mathrm{Em}$ síntese, o que parece claro é que existem duas condições para a gramaticalidade dos OC verdadeiros em PE (definitude e modificação) e que estes se devem distinguir das expressões lexicalizadas.

Apresentamos o quadro seguinte como síntese das propriedades restritivas típicas dos verdadeiros OC em PE:

Quadro 2 - Propriedades sintático-semânticas dos OC verdadeiros em PE

\begin{tabular}{|l|l|}
\hline Propriedades: & OC verdadeiro em PE \\
\hline Definitude & indefinido \\
\hline Modificação & Presença de adjetivo / SP / OR \\
\hline Categoria e estrutura do constituinte & SN [Det ind $_{\text {+N+Adj/SP/OR] }}$ \\
\hline Classe e subclasse do núcleo & $\begin{array}{l}\text { Nome comum: } \\
\text { contável ou não contável }\end{array}$ \\
\hline
\end{tabular}

Vejamos mais de perto outras construções em PE, a fim de refletir sobre os vários tipos de construções cognatas que podem existir nesta língua.

\section{Tipos diferentes de objetos cognatos e objetos hipónimos em PE}

Tem sido notado na literatura que os objetos cognatos são de vários tipos, uns cognatos (verdadeiros ou aparentados), como (1) a (4), outros objetos hipónimos (OH) (Hale / Keyser, 2002), como em (15) e (16):

32 Exemplo da Web, http://desmondier.blogspot.com/2010/06/chuva.html (27/02/2012).

33 Exemplo da Web, http://foradabolha.blogspot.com/2008_12_01_archive.html (27/02/2012). 
(15) Ele dançou um tango.

(16) He danced a jig. (Hale / Keyser, 2002: 71)

[Ele dançou uma $j i g$ ]

De facto, nestes exemplos temos objetos que referenciam um tipo específico de dança - um tango e a jig - estabelecendo com o verbo uma relação semântica, muito marcada culturalmente em cada comunidade, e não uma relação morfológica como em chover - chuva, em PE, ou to sleep- sleep, no Inglês. Por outro lado, este tipo de objetos parece não reagir da mesma forma que os verdadeiros $\mathrm{OC}$, quanto aos critérios da modificação restritiva, podendo surgir sem modificador adjetival ou preposicional como nos exemplos (15) e (16), contrariamente ao que se verifica nos OC (cf. de novo os exemplos em (1)). Relativamente à definitude, também não parece ser um critério exigido por este tipo de objetos hipónimos. Vejamos os exemplos (17) e (18), em contraste com os dados em (5) e (6):

(17) a) Ele dançou um tango alegre.

b) Ele dançou um tango.

b) Ele dançou o tango alegre.

c) Ele dançou o tango.

(18) a) Ele dançou uma dança alegre.

b) Ele dançou uma dança.

c) Ele dançou a dança alegre.

d) Ele dançou $a$ dança.

A agramaticalidade dos exemplos em (5) e (6), com os verbos chover e dormir, respetivamente, comprova que os verdadeiros OC são muito mais restritivos do que as construções como os $\mathrm{OH}$, dançar um tango em (17), e os OC aparentados, dançar uma dança em (18).

Embora a distinção entre $\mathrm{OC}$ e $\mathrm{OH}$ seja fundamental e seja referida frequentemente na literatura, pensamos que outras distinções se justificam em PE. Há uma diferença entre objetos verdadeiramente cognatos, como os já referidos (chover-chuva) e outros que, embora acompanhando verbos 
tradicionalmente considerados intransitivos ou de alternância transitiva / intransitiva, não são verdadeiros cognatos, como é o caso dos cognatos aparentados - dançar uma dança (18).

Os OC aparentados não devem ser confundidos com os OC verdadeiros. No entanto, outra distinção se justifica. Consideramos que exemplos como os de (19), com o par chorar - lágrimas, não podem ser considerados verdadeiros cognatos: em primeiro, porque verbo e nome não são cognatos, apenas se relacionam semanticamente, lágrimas aparece como o produto (uma entidade semântica) que resulta do evento simples chorar; em segundo, o SN não apresenta as mesmas propriedades sintático-semânticas, nomeadamente a indefinitude e o nome-núcleo no singular.

(19) A vítima chorou lágrimas de raiva. (Duarte / Brito, 2003:185)

Os objetos não cognatos do tipo lágrimas de raiva são muitas vezes confundido com os objetos cognatos verdadeiros (por exemplo em Duarte / Brito 2003:185) porque, por um lado, são também pleonásticos, porque verbo e nome se relacionam, de algum modo, semanticamente, o que justifica a agramaticalidade perante a ausência de modificador, (20); e, por outro, porque os verbos têm uma variante intransitiva / inergativa, que pode surgir isolada e sem qualquer objeto, sendo, neste caso, o mesmo verbo que admite OC verdadeiro (cf. chorar - choro vs. chorar-lágrimas).

(20)*A vítima chorou lágrimas.

Aplicados os testes de pronominalização, por exemplo, verificamos que o OC verdadeiro não permite a pronominalização (21) e o objeto com o núcleo lágrimas admite (22).

(21) a) A vítima chorou um choro profundo. (OC verdadeiro)

b) *A vítima chorou-o.

(22) a) A vítima chorou lágrimas de raiva. (outro objeto)

b) A vítima chorou-as. 
Estes dados, ao permitirem diferenciar os dois tipos de construções, podem estar também a aproximar o objeto lágrimas de raiva a um verdadeiro OD. Esta hipótese precisa de ser explorada, sendo que os limites de espaço deste artigo não nos permitem.

Deve ainda distinguir-se a natureza categorial dos objetos em análise. De facto, até este momento, todos os exemplos em causa comportavam SNs como objetos. No entanto, verbos como morrer, nascer e caminhar, dependendo das línguas em que ocorrem, podem combinar-se com SPREPs ou com SNs (Real-Puigdollers, 2008: 159; Choupina, 2013:65):

(23) a) They walked [on] a difficult way. [Inglês]

b)?Caminharam um caminho difícil. [Português do Brasil]

c) Caminaban por un caminho difícil. [Espanhol]

d) Caminhavam por um caminho difícil. [Português]

e) Ils marchaient par un chemin dur. [Francês]

Em Inglês, (23a), temos verdadeiros cognatos, sem necessidade de realização de preposição; a aceitar-se o exemplo (23b) como gramatical, também o Português do Brasil admite SN cognato com o verbo caminhar. Porém, noutras línguas românicas, como o Espanhol, o PE e o Francês ${ }^{34}$, e com este verbo, os OC são, obrigatoriamente, grupos preposicionais, (23c/d/e); chamá-los-emos, provisoriamente, objetos cognatos preposicionais (OCP).

Enquanto em Inglês, quando se trata de verdadeiros cognatos, os verbos são denominais (cf. to laugh-laugh), em PE e noutras Línguas Românicas colocam-se problemas novos ao tratamento dos objetos cognatos, porque há várias construções aparentadas e porque nem sempre

\footnotetext{
${ }^{34}$ Em Francês, os OCP são muito comuns, vejam-se os exemplos seguintes, em que no Espanhol e no Inglês temos $\mathrm{SN}$ :

(1) a) Reir la risa de un niño. [Espanhol] (Mendikoetxea, 1999:1578)

b) Rire d'un rire d'enfant. [Francês]

(2) a) She slept the sleep of the just. [Inglês] (Hale / Keyser, 2002:71)

b) Elle a dormi $d u$ sommeil du juste. [Francês]

(3) a) He laughed his last laugh. [Inglês] (Hale / Keyser, 2002:71)

b) Il a rit de son dernier rire. [Francês]
} 
há homonímia perfeita entre a raiz verbal e a raiz nominal. Assim, em PE, quando há verdadeiros cognatos, o processo de formação parece ser da raiz para a formação de $\mathrm{V}$ ou de $\mathrm{N}$, ou da raiz verbal para o $\mathrm{N}$, mas não necessariamente do N para o V (ver a este propósito Rodrigues, 2001).

Assim, fazemos a seguinte proposta de organização das construções do PE que nalguma literatura são designadas objetos cognatos:

(i) OC verdadeiros: a) o nome está morfologicamente relacionado com o verbo; são estruturas que exigem indefinido e modificador restritivo; sonhar-sonho..., chover-chuva..., tossir-tosse...; b) o nome relaciona-se semanticamente com o verbo e na língua não é possível a substituição por um cognato morfológico; dormir-sono... ...**dormir-dormida...

(ii) OC aparentados: o nome está, aparentemente, morfologicamente relacionado com o verbo; são estruturas que podem ocorrer, embora não obrigatoriamente, com determinante indefinido e modificador restritivo; dançar-dança, cantar-canção...

(iii) OH: o nome exprime um subtipo da entidade denotada pelo nome morfologicamente relacionado com o verbo ou semanticamente dependente dele; não exigem definitude nem modificação restritiva; dançar-tango, comer-lasanha, cantar-fado...

(iv) OCP: é um SP que contém um nome morfologicamente relacionado com o verbo e integra um determinante indefinido e um modificador restritivo, distinguindo-se dos verdadeiros OC pelo facto de serem encabeçados por uma preposição, exigida pelo verbo em PE, embora tal exigência não seja comum a outras línguas; caminhar por um caminho, morrer de uma morte...

Na próxima secção do texto, vamos discutir a análise de algumas destas construções feita por Hale e Keyser $(1993,2002)$, para o Inglês, dentro dos limites impostos por este artigo. 


\section{Proposta de Hale e Keyser (1993, 2002)}

Os OC e os $\mathrm{OH}$ são largamente estudados na literatura, nomeadamente a partir do tratamento que sobre eles é feito por Hale e Keyser. A partir deste ponto, seguiremos de perto a apresentação feita por nós em trabalhos anteriores (Choupina, 2012a; 2012b; 2013).

Como se sabe, em Inglês há uma vasta gama de itens lexicais que tanto pertencem à categoria dos nomes como dos verbos, como é o caso de dance, laugh, bottle e saddle.

Hale e Keyser (1993) propõem que os verbos inergativos denominais em inglês (como dance, laugh) sejam considerados subjacentemente "transitivos" ou "transitivos escondidos", sendo formados através de um processo lexical (abstrato) ("1-syntactic") de incorporação, isto é, por um movimento de núcleo, sendo que ficam alguns traços na posição no nome $\left(t_{\mathrm{i}}\right)$, como é ilustrado na derivação de a. para b. em (24).

(24)

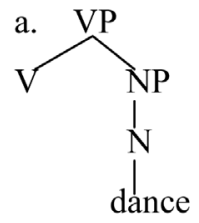

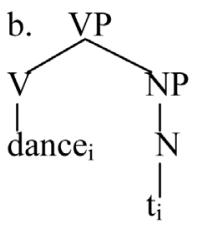

No quadro de Hale / Keyser (2002), a proposta é ligeiramente adaptada. Todos estes verbos são identificados como verbos denominais e com uma estrutura argumental monádica, projetando um argumento. O que acontece é que, no léxico, o núcleo (V) não projeta um especificador e o complemento não motiva uma projeção, o que leva a que não seja licenciado um argumento interno. Neste sentido, o argumento sujeito é introduzido na sintaxe e é externo.

Inicialmente vista como resultado de uma operação de incorporação (movimento de um núcleo para uma posição de núcleo), como descrito em (24), a noção de incorporação é mais tarde refinada de modo a captar a existência de objetos cognatos em Inglês e passa a designar um processo de cópia (to dance-dance); os autores introduzem então a noção de conflation, consistindo tal noção «in the process of copying the 
p-signature of the complement into the p-signature of the head, where the latter is "defective"» (Hale / Keyser, 2002:63).

Mas este tratamento tem um problema importante, referido por muitos autores. Como já vimos no ponto 1., o maior problema desta análise é que os mesmos verbos que apresentam OC com restrições, formam livremente objetos hipónimos (ver (25)), os quais negam a possibilidade de que os verbos denominais sejam formados na posição de complementos ${ }^{35}$ e que sejam o resultado de uma incorporação nominal numa raiz verbal vazia:

(25)

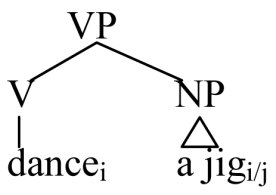

Os próprios autores reconhecem que OC e OH são distintos, a partir de exemplos como o de $(26)^{36}$, não só porque algumas construções com verdadeiros OC não permitem construções com objetos hipónimos (27), mas também porque rejeitam a pronominalização em construções com OC (28), enquanto as construções com OH permitem (29). (cf. Hale e Keyser, 2002: 71)

(26) to sleep + OC [dormir + OC]

She slept the sleep of the just. [Ela dormiu o sono dos justos]

(27) *to sleep + $\mathrm{OH}[*$ dormir $+\mathrm{OH}]$

* She slept her last nap / a long winter slumber. [Ela dormiu a sua última sesta / um longo sono de inverno]

35 De acordo com Hale / Keyser, os objetos cognatos não colocam tal problema; veja-se, por exemplo: "He laughed his last laugh". Segundo a teoria da cópia por movimento (Chomsky, 1995), tais construções podem spell out ambas as cópias do elemento movido (Hale / Keyser, 2002: 72; Haugen, 2007: 246; para uma síntese Choupina 2012a).

36 Este exemplo, no nosso entender e como já referimos na primeira nota de rodapé deste texto, levanta algumas questões interessantes e abre caminho para um outro tipo de análise: as fronteiras entre as estruturas com OC e as expressões fixas ou adaptações destas. Entendemos a expressão dormir o sono dos justos como uma expressão fixa, que, aliás, ocorre traduzida em diversas línguas do mundo. 
(28) *to sleep + OC + pronominalização [*dormir + OC+ pronominalização]

* John slept the sleep of the just and Bill slept it too. [*O João dormiu o sono dos juntos e o Bill também o dormiu]

(29) to dance $+\mathrm{OH}+$ pronominalização $[$ dançar $+\mathrm{OH}]$

John danced the tango and Bill danced it too. [O João dançou o tango e o Bill também o dançou]

Para Hale e Keyser (2002), conflation é uma operação de seleção e obedece a complementação estrita, definida como sendo: " $\mathrm{A}$ head $\mathrm{X}$ is the strict complement of a head $\mathrm{Y}$ if is in a mutual c-command (i.e., sister) relation with the maximal categorical" (Hale / Keyser, 2002:59).

Para os autores, os OC verdadeiros em Inglês podem ser tratados por incorporação / conflation ${ }^{37}$, não sendo verdadeiramente argumentos; os $\mathrm{OH}$ são argumentos selecionados pelos Vs.

Contudo, a existência de quatro tipos de construções diferentes em PE e noutras línguas românicas obriga-nos a repensar este quadro. Por um lado, ao associar à conflation a seleção de argumentos, os autores fragilizam a componente do léxico e, consequentemente, a abordagem que desenvolvem das construções em estudo, uma vez que usam noções e operações marcadamente sintáticas. Por outro lado, nas línguas românicas não há, na maioria das vezes, homonímia perfeita entre a raiz verbal e o OC, ao contrário do Inglês, que exibe tantos verbos denominais.

Neste sentido, propomos o abandono de uma proposta estritamente lexicalista como a de Hale e Keyser para o tratamento das várias construções cognatas em PE. Embora não seja possível apresentar abordagens alternativas, pelos limites de espaço deste texto, pensamos que os modelos da Morfologia Distribuída podem trazer algum contributo para a reflexão aqui encetada.

37 Segundo Haugen (2009), no quadro da Morfologia Distribuída, a revisão da noção de conflation de Hale / Keyser (2002) não é inteiramente satisfatória, em particular porque uma complementação estrita limitada por conflation não exclui a possibilidade de um "resíduo" (por exemplo um adjetivo). 


\section{Considerações finais}

$\mathrm{O} P E$ e as línguas românicas em geral levantam novas questões no campo do estudo dos verbos com $\mathrm{OC}$ e $\mathrm{OH}$.

Considerando os critérios de definitude e de modificação e a relação morfológica e / ou semântica que o verbo estabelece com o OC, justificam-se quatro tipos de construções em PE: verdadeiros OC (sonhar-sonho...); OC aparentados (dançar-dança); OH (dançar um tango...) e OCP (caminhar por um caminho...).

A teoria que Hale e Keyser $(1993$; 2002) desenvolveram, num quadro lexicalista forte, para dar conta destes fenómenos em Inglês, não permite analisar adequadamente vários aspetos sintáticos e semânticos relacionados com estes quatro tipos de construções em PE, tornando-se necessário explorar outras abordagens.

\section{Referências bibliográficas}

Choupina, C. (2012a): Quelques apports de la Morphologie Distribuée pour l'analyse syntaxique des objets cognats en PE. Comunicação apresentada ao Symposium L'interface de la syntaxe et de la sémantique lexicale. Synchronie E diachronie. Poznan (março de 2012).

Choupina, C. (2012b): Os objetos cognatos em Línguas Românicas e no Inglês: aspectos sintáticos e semânticos contrastivos. Comunicação apresentada ao VII $\mathrm{e}^{\mathrm{C}}$ Colloque International Linguistique contrastive germano-romane et intraromane. Innsbruck (setembro de 2012).

Choupina, C. M. (2013): Contributos para uma análise sintática dos objetos cognatos em PE. In: Studia Romanica Posnaniensia, XL/1, 59-79.

Duarte, I. / Brito, A. M. (2003): Predicação e classes de predicadores verbais. In: Mateus, M.H.M, et al. (edd.): Gramática da Língua Portuguesa. Lisboa: Caminho, 179-203.

Duarte, I. / Oliveira, F. (2003): Referência nominal. In: Mateus, M.H.M, et al. (edd.): Gramática da Língua Portuguesa. Lisboa: Caminho, 206-242.

Galego, A. (2008): Cognate Objects and (Clitic) Doubling. Intervention présentée au Norms. Workshop on Argument Structure. Lund University (February 2008).

Grevisse, M. / Goosse, A. (1993): Le bon usage. Bruxelles: De Boeck-Duculot.

Hale, K. / Keyser, S. J. (1993): On Argument Structure and the Lexical Expression of Syntactic Relations. In: Hale, K. / Keyser, S.J. (edd.): The View From Building 20: Essays in Linguistics in Honor of Sylvain Bromberger. Cambridge. Mass.: MIT Press, 53-109.

Hale, K. / Keyser, S.J. (2002): Prolegomenon to a theory of argument structure. Cambridge, Mass.: MIT Press.

Haugen, J. D. (2009): Hyponymous objects and Late Insertion. In: Lingua 119 (2), 242-262. 
Mendikoetxea, A. (1999): Construcciones inacusativas y pasivas. In: Bosque, I / Demonte (edd.): Gramática descritiva de la lengua española. Madrid: Espasa Calpe, 1575-1629.

Pereltsvaig, A. (2001): Cognate objects in Modern and Biblical Hebreu. In: Ouhalla, J. / Shlonsky, U. (edd.): Themes and Issues in Arabic Hebrew. Kluwer: Academic Publishers, $1-31$.

Pustejovsky, (1998): The Generative Lexicon. Cambridge, Mass: MIT Press.

Real-Puigdollars, C. (2008): The Nature of Cognate Objects. A Syntactic Approach. In: Proceedings ConSOLE XVI, 157-178. [On-line], disponível em: <http://www.sole.leidenuniv. nl>. [consultado em: 27 maio 2011].

Rodrigues, A. (2001): A construção de postverbais em português. Porto: Granito Editores e Livreiros. 